\title{
Sex Differences of Migraine: Results of a Nationwide Home-based Study in Turkey
}

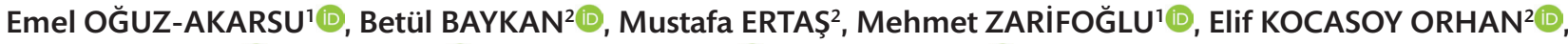 \\ Sabahattin SAiP ${ }^{3}$, Aksel SiVA ${ }^{3}{ }^{-}$, Ayşe Emel ÖNAL ${ }^{4}{ }^{-}$, Necdet KARLI'(i)
}

'Department of Neurology, Uludağ University, Uludağ School of Medicine, Bursa, Turkey

2Department of Neurology, İstanbul University, İstanbul Faculty of Medicine, İstanbul, Turkey

${ }^{3}$ Department of Neurology, İstanbul University, Cerrahpaşa School of Medicine, İstanbul, Turkey

${ }^{4}$ Department of Community Health, İstanbul University, İstanbul Faculty of Medicine, İstanbul, Turkey

\section{ABSTRACT}

Introduction: The prevalence of migraine was found to be more than three-fold higher in women as compared with men, and in addition to differences in prevalence rates, the characteristics and associated features might also differ between the sexes. The aim of this study was to compare sex-specific features of migraine and demographic parameters in a nationwide population-based study in Turkey.

Methods: Among 5323 subjects, a total of 871 patients who were diagnosed as having definite migraine according to the diagnostic criteria of the International Classification of Headache Disorders-III (ICHD-III) were included in our study. The demographic characteristics, associated features, and triggers of migraine were examined with regard to sex.

Results: The study group comprised 640 women (73.5\%) and 231 men $(26.5 \%)$, with a female to male ratio of $2.8: 1$. Attack duration, mean migraine disability assessment scores (MIDAS), frequencies of nausea, vomiting, osmophobia, vertigo/dizziness, and allodynia were found significantly different between women and men. When we compared these parameters between men and postmenopausal women, all these parameters were still significant except nausea. Odor was statistically more frequent as a reported trigger in women, whereas excessive sleep was a statistically more frequent triggering factor in men. The rates of depression and allergy were significantly higher in women when compared with men.

Conclusion: Longer attack duration, higher MIDAS scores, and the frequencies of nausea, vomiting, osmophobia, vertigo/dizziness, and allodynia were more significant in women and this variance in sex persisted after menopause. Also, some trigger factors and comorbidities differed between the sexes. These findings might result from complex genetic factors besides sociocultural influences, biologic, and sociocultural roles. Future studies should continue to explore biologic and genetic factors with respect to sex in migraine.

Keywords: Migraine; sex differences; postmenopausal women

Cite this article as: Oğuz Akarsu E, Baykan B, Ertaş M, Zarifoğlu M, Kocasoy Orhan E, Saip S, Siva A, Önal AE, Karlı N. Sex Differences of Migraine: Results of a Nationwide Home-based Study in Turkey. Arch Neuropsychiatry 2020;57:126-130.

\section{INTRODUCTION}

Migraine is a common and disabling disorder, constituting a major health problem for individuals and society. Studies of migraineurs in the general population have consistently demonstrated that migraine is more prevalent in women as compared with men $(1,2)$. The prevalence of migraine was found to be more than three-fold higher in women and, in addition to differences in prevalence rates, the characteristics and associated features might also differ between two sexes (1-3). Many factors could account for these differences including fluctuations in sex hormones, receptor binding, genetic predisposition, environmental factors, and pain perception, as well as differences in brain function and structure (4-6).

Although it is well-established that migraine is highly prevalent, especially in younger women, the differences of symptomatology, associations, and disability between men and women are poorly understood (1, 2). Moreover, several unresolved questions remain because there are only a handful of population-based studies comparing migraineurs in relation to sex (3). Therefore, in the current study, we aimed to compare sex-specific features of migraine and demographic parameters in a nationwide population-based study in Turkey.

\section{METHODS}

In 2008, we designed a nationwide, community-based prevalence study in subjects aged 18-65 years conducted through face-to-face interviews with 33 trained general physicians. Twenty-one cities from seven geographic regions of Turkey representing the characteristics of households were selected based on the ratio of their population to the total population of Turkey (7).

The evaluation of households was made by using a structured electronic questionnaire. The comprehensive interview form included questions 
for diagnoses of migraine according to the diagnostic criteria of the International Classification of Headache Disorders (ICHD)-II. The recently published ICHD-III diagnostic criteria were examined and the evaluations of the forms were made according to ICHD-III (8). In addition to the characteristics and associated features of headaches, we also assessed the demographic and socioeconomic status of the subjects, comorbidities, hormonal changes, and disability using the validated Turkish version of the Migraine Disability Assessment (MIDAS) questionnaire (9).

To prevent any genetic effect, only one subject was interviewed and a Kish sampling grid was used to select the subject. From 6000 households, a total of 5323 subjects were investigated after excluding households that were surveyed but not interviewed because of various reasons. As a result, statistical analyses were performed with a standard error of $\pm 1.3 \%$ and the results are presented with 95\% confidence intervals.

The postmenopausal period was defined as the point of time when menstruation ceased after 12 months of amenorrhea.

For this study, we evaluated migraineurs in relation to sex and compared the demographic characteristics, associated features, and trigger factors. Significant parameters were also evaluated between men and postmenopausal women.

Descriptive statistics were applied for the investigated parameters and the Chi-square test and t-test were performed for categorical variables where appropriate. For group comparisons, the Shapiro-Wilk test was used to determine whether the data were normally distributed. Binary logistic regression tests were performed to explore the differentiating variables between female and male migraineurs. The Statistical Package for the Social Sciences (IBM SPSS Statistics, New York, USA) 21.0 software was used for statistical evaluations, and $p \leq 0.05$ was accepted as the limit of significance.
Ethics Committee approved this study and written informed consent was obtained from all participants.

\section{RESULTS}

Among 5323 subjects, a total of 871 were diagnosed as having definite migraine. The study group comprised 640 women (73.5\%) and 231 men (26.5\%), corresponding to a female to male ratio of $2.8: 1$. The ages of the subjects ranged between 18 and 65 years. The mean ages of the women and men were $37.02 \pm 11.4$ years and $36.74 \pm 10.8$ years, respectively.

The general characteristics of the patients in relation to sex are shown in Table 1.

Table 2 shows a comparison of the associated features of migraine in relation to sex. Among the investigated parameters, longer attack duration and higher MIDAS scores, and the frequencies of nausea, vomiting, osmophobia, vertigo/dizziness and allodynia were found significantly different between women and men. The significant parameters between women and men were also compared between men and postmenopausal women, which are also shown in Table 2 as p'. All these parameters were still significant except nausea.

As seen in Table 3, stress (68.5\%), wind (54.4\%), hunger (54.2\%), and sleeplessness (53.0\%) were common trigger factors across the entire group and there was no significant difference between women and men. Odor was reported to be a trigger in women statistically more frequently than in men, whereas excessive sleep was statistically more frequently reported as a trigger in men.

Binary logistic regression analyses were performed with important clinical variables. $\mathrm{P}$ values, odds ratios (ORs) and lower-upper $95 \% \mathrm{Cl}$ values according to the binary logistic analyses were as follows; allodynia $(P=0.171$, OR: $0.797,95 \% \mathrm{Cl}: 0.576-1.103)$, osmophobia $(P=0.044, O R$ :

Table 1. Demographic characteristics of women and men with migraine

\begin{tabular}{|c|c|c|c|c|c|}
\hline & & $\begin{array}{c}\text { Women (n: 640) } \\
n(\%)\end{array}$ & $\begin{array}{c}\text { Men (n: 231) } \\
\text { n (\%) }\end{array}$ & Total (n: 871) n (\%) & $\mathbf{p}$ \\
\hline Age & $18-29 y$ & $191(29.8)$ & $70(30.3)$ & $261(30)$ & \\
\hline & $30-39 y$ & $186(29.1)$ & $71(30.7)$ & $257(29.5)$ & \\
\hline & $40-49 y$ & $157(24.5)$ & $52(22.5)$ & $209(24)$ & \\
\hline & $50-65 y$ & $106(16.6)$ & $38(16.5)$ & $144(16.5)$ & \\
\hline Marri & & $449(70.2)$ & $160(69.3)$ & 609 (69.9) & NS \\
\hline Educe & & & & & \\
\hline & & $258(40.3)$ & $55(23.8)$ & $313(35.9)$ & \\
\hline & & $382(59.7)$ & $176(76.2)$ & $558(64.1)$ & $<0.000^{*}$ \\
\hline Incon & & & & & \\
\hline & & $484(75.6)$ & $173(74.9)$ & $657(75.4)$ & \\
\hline & & $156(24.4)$ & $58(25.1)$ & $214(24.6)$ & NS \\
\hline Living & & & & & \\
\hline & & $459(71.7)$ & $151(65.4)$ & $610(70)$ & \\
\hline & & $181(28.3)$ & $80(34.6)$ & $261(30)$ & NS \\
\hline Curre & & $217(33.9)$ & $133(57.6)$ & $350(40.2)$ & $<0.001^{*}$ \\
\hline Alcoh & & $90(14.1)$ & $75(32.5)$ & 165 (18.9) & $<0.001^{*}$ \\
\hline Depre & & $209(33.3)$ & $34(14.8)$ & $243(28.3)^{*}$ & $<0.001^{*}$ \\
\hline Epilep & & $8(1.3)$ & $1(0.4)$ & $9(1)$ & NS \\
\hline Olfact & & $528(82.5)$ & $167(72.3)$ & $695(79.8)$ & 0.001 \\
\hline Intole & & $533(83.3)$ & 165 (71.4) & $698(80.1)$ & $<0.001^{*}$ \\
\hline Allerg & & $208(32.5)$ & $58(25.1)$ & $266(30.5)$ & $0.037^{*}$ \\
\hline Allerg & & $55(8.6)$ & $13(5.6)$ & $68(7.8)$ & NS \\
\hline Hype & & $97(15.2)$ & $26(11.3)$ & $123(14.1)$ & NS \\
\hline Physic & & $467(73)$ & $148(64.1)$ & $615(70.6)$ & $0.011^{*}$ \\
\hline Neurc & & $229(35.8)$ & $59(25.5)$ & $288(33.1)$ & $0.005^{*}$ \\
\hline
\end{tabular}


Table 2. Associated features with migraine in relation to sex

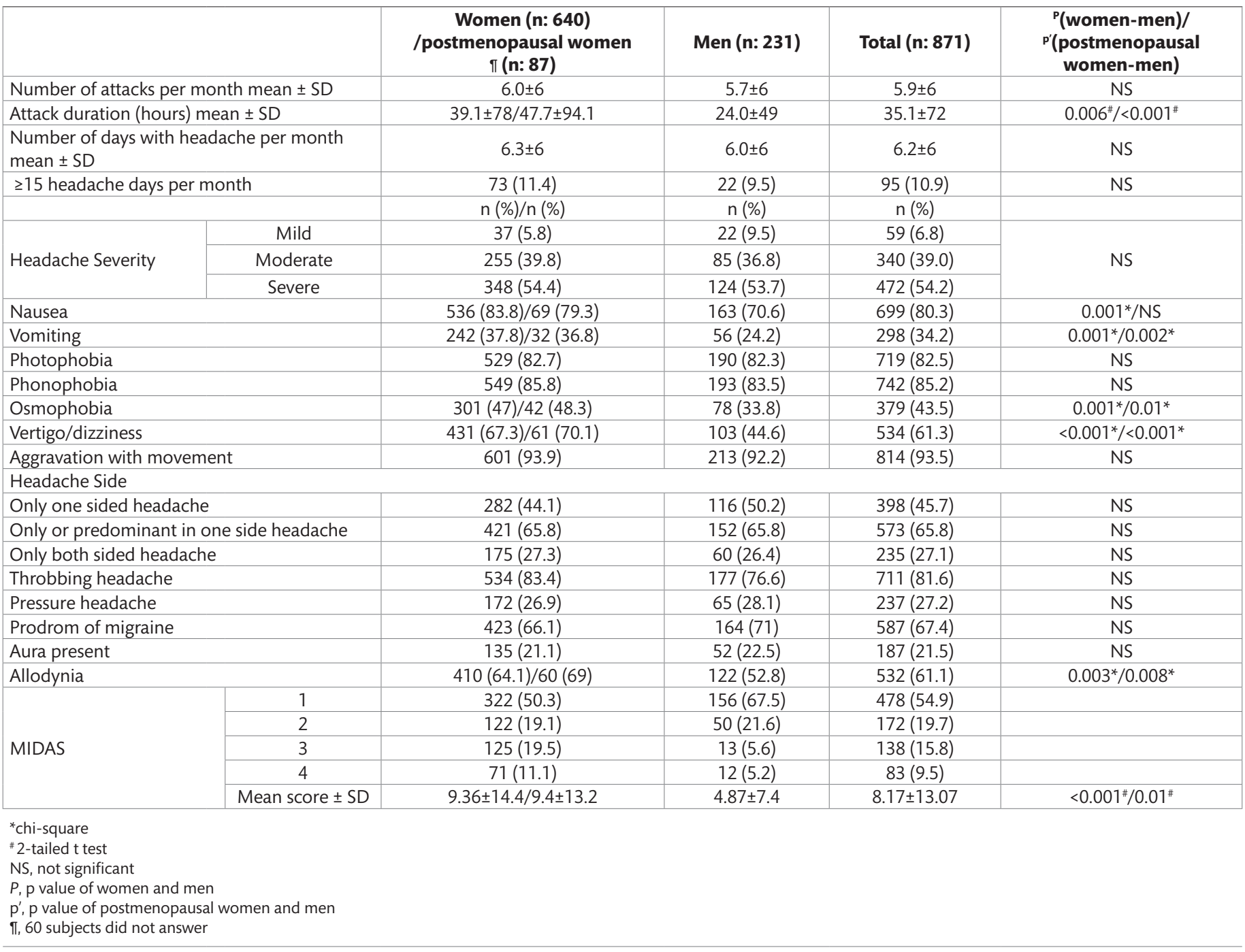

Table 3. Potential trigger factors of migraine in relation to sex

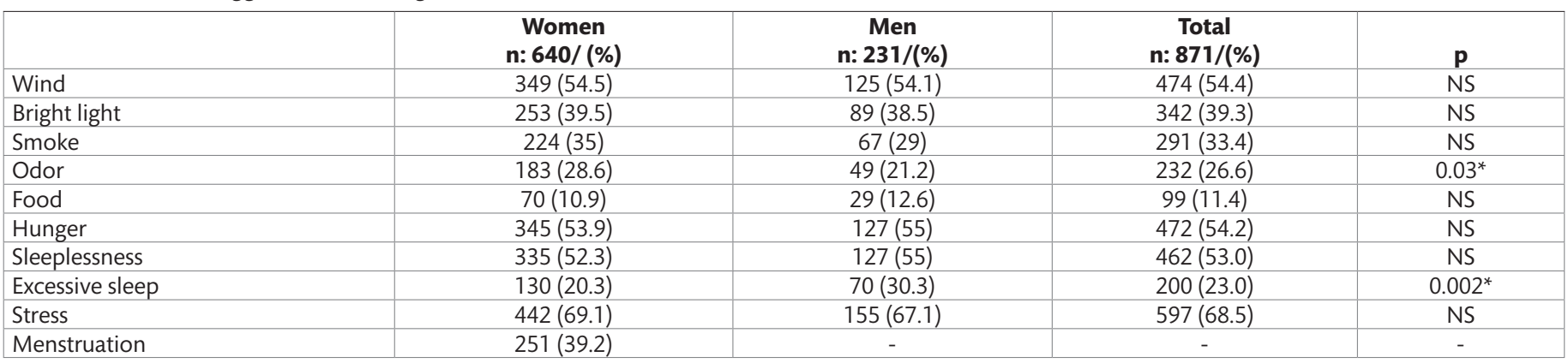

* chi-square.

NS, not significant.

1.414, 95\% Cl: 1.01-1.981), depression ( $P<0.001$, OR: $2.564,95 \%$ Cl: $1.696-$ 3.875), vertigo $(P<0.001, O R: 0.503,95 \%$ Cl: $0.364-0.695)$, nausea $(P=0.007$, OR: 1.681, 95\% Cl: 1.152-2.453) and attack duration ( $>24$ hours) $(P=0.003$, OR: $1.759,95 \% \mathrm{Cl}: 1.206-2.566)$. Only allodynia lost its significance after binary logistic regression analysis.

\section{DISCUSSION}

Our results showed that women had longer migraine attacks with more associated symptoms such as nausea, vomiting, osmophobia, vertigo/ dizziness, and allodynia, which causes more disability. Contrary to our hypothesis, these associated features were still significant when we compared postmenopausal women with men, except for nausea.

Several studies focused on the role of sex hormones in the pathophysiology of migraine $(10,11)$. Migraine frequency is lower and does not differ between the sexes before puberty. In women, its frequency increases during menstruation and lowers after physiologic menopause. The high migraine prevalence among women is attributed to fluctuating levels of gonadal hormones $(12,13)$. There is a complex relationship between 
estrogen and migraine. For example, menstrual migraine is related with falling levels of estrogen, and oral contraceptive use results in aggravation in patients who have migraine with aura (14). It was also emphasized that the hormonal system modulates cortical, subcortical, and brainstem functions, and these modulations at cellular and functional levels might lead to some of the associated features related with migraine $(15,16)$. In addition, estrogen has a direct effect on the trigeminovascular system. Accordingly, migraine attacks may be accompanied by a variety of autonomic symptoms (e.g., nausea, vomiting, rhinorrhea, and ptosis), affective disorders and symptoms (e.g., depression and irritability), cognitive symptoms (e.g., difficulty in finding words, transient amnesia), and sensory symptoms (e.g., photophobia, phonophobia, osmophobia, and cutaneous allodynia) $(15,16)$. Our results showed that women had longer migraine attacks with more associated symptoms such as nausea, vomiting, osmophobia, vertigo/dizziness, and allodynia. When we compared these parameters between men and postmenopausal women, all these parameters were still significant except nausea. Although we do not have a single answer, we think a simple correlation between gonadal hormones and migraine does not seem to be sufficient for such a discrepancy between women and men.

Several studies may further support our thesis that some genetic risk factors influence the liability to migraine and its characteristics in relation with sex. Complex genetic factors are involved in migraine in up to $60 \%$ of cases $(17,18)$. Genetic factors, including ion-channel function, appear to set the individual threshold; internal and environmental factors including hormonal fluctuations may modulate this genetic predisposition (18). In addition, many years of hormonal fluctuations during the fertile period might result in irreversible changes in cortical, subcortical, and brainstem cells and circuits.

In our study, the rates of nausea and vomiting were significantly higher in women when compared with men. In the postmenopausal period, vomiting was still significantly high in women. Higher vagal tone in women as well as the well-known effects of gonadal hormones are reported to be associated with nausea and vomiting in women (19). Mitochondrial DNA sequence variations in migraine and cyclic vomiting syndrome support the genetic predisposition of vomiting in migraine patients (20). Our findings confirm the genetic effect of vomiting in female migraineurs, which starts in puberty and persists after menopause, is not solely an effect of sex hormones.

Allodynia is a marker of central sensitization in migraine patients. According to our findings, allodynia was more commonly seen in women even in the postmenopausal period. However, allodynia lost its statistical significance when binary logistic regression was performed to explore the differentiating variables between women and men. This might be as a result of associations of allodynia with longer duration of attacks, nausea, and vomiting, which have been shown in previous studies $(21,22)$.

Vertigo is two or three times more commonly reported as an associated symptom in migraine patients when compared with headache-free controls. Consistent with our results, previous studies have also reported a marked female predominance in vertiginous migraine (23).

Typical triggers such as stress, wind, hunger, and sleeplessness were common trigger factors across the entire group and they did not differ between women and men, concordant with previous studies $(24,25)$. Odor was a statistically more frequent trigger factor in women, whereas excessive sleep was a statistically more frequent trigger factor in men.

Odor is of importance in migraine in several ways besides being a trigger factor. As a trigger factor for migraine attacks, and in osmophobia during attacks, intolerance to odors and olfactory hypersensitivity are commonly reported. According to our study, all these factors associated with odor were significantly higher in women when compared with men. Although most studies supported our findings, Kelman reported no significant difference between women and men in respect to odor triggers (26). In a population-based study in Sweden, odor intolerance was found to be two-fold higher in women (27). The mechanism of female predominance is not well understood but it is remarkable that osmophobia has a strong relationship with women. According to the diagnostic criteria of the Canadian Headache Society, osmophobia was included as a specific feature of migraine, also, the diagnostic and therapeutic guidelines of the Italian Society for the Study of Headaches recommended osmophobia among the additional supporting criteria for the diagnosis of migraine $(28,29)$. ICHD-III does not include osmophobia in the diagnostic criteria although these classifications recommended osmophobia as a specific feature of migraine. Our data support that osmophobia cannot be considered a peculiar symptom of migraine because of the high discrepancy in sex.

Excessive sleep was found to be a statistically more frequent trigger factor in men when compared with women. The exact explanation for this association between men and excessive sleep is not clear but it might be due to women's sleep patterns. Taking care of an infant or elderly relatives, which disturbs sleep, and different responsibilities and rights of women might condition them to require less sleep (30).

Migraine is co-morbid with various medical conditions, and there are more co-morbid diseases in migraine women compared with men. In our population, the rates of depression and allergy were significantly higher in women, in concordance with previous studies (5).

As a conclusion, this population-based study showed that longer attack duration, higher MIDAS scores, and the frequencies of nausea, vomiting, osmophobia, vertigo/dizziness, and allodynia were more significant in women, and this variance in sex persisted after menopause. Also, some trigger factors and co-morbidities differed between the sexes. This finding seems to result from complex genetic factors as well as sex hormones and receptor binding and psychosocial effects. We suggest that future studies should continue to explore biologic and genetic factors with respect to sex in migraine. As more is learned about the biology and genetics of migraine and about the differences between the sexes, we will be able to diagnose, treat, and estimate outcomes for both sexes more accurately.

Acknowledgements: The authors thank our physician team, interviewers, technical team, and finally all participants, who made this study valuable. This study was made possible by the efforts of Rana Şengil (Pharm) and Işıl Çelik Uzunçakmak (Pharm) from I. E. Ulagay-Menarini Group, Davutpaşa Cad No: 12 Topkapı-İstanbul, in coordination and by the hard work of Objektif Research \& Information Services, Cumhuriyet Cad No: 2 Harbiye-istanbul, in data collection from the field.

Ethics Committee Approval: Ethics committee approved this study.

Informed Consent: Written informed consent was obtained from all participants.

Peer-review: Externally peer-reviewed.

Author Contributions: Concept - EOA, ME, BB, NK; Design - EOA, ME, BB, NK; Supervision - EOA, ME, BB, NK; Resource - I.E Ulagay - Menarini Group; Data Collection and/ or Processing - BB, ME, AS, SS, NK, MZ, EKO, AEO; Analysis and/or Interpretation - EOA, BB, NK; Literature Search - EOA, BB, NK; Writing - EOA, BB, NK; Critical Reviews - EOA, BB, EKO, NK

Conflict of Interest: No conflict of interest was declared by the authors.

\section{REFERENCES}

1. Baykan B, Ertas M, Karli N, Akat-Aktas S, Uzunkaya O, Zarifoglu M, Siva A, Saip S; the MIRA-Neurology Study Group. The burden of headache in neurology outpatient clinics in Turkey. Pain Pract 2007;7:313-323. [CrossRef]

2. Lipton RB, Bigal ME. Migraine: epidemiology, impact, and risk factors for progression. Headache 2005;45:S3-S13. [CrossRef] 
3. Buse DC, Loder EW, Gorman JA, Stewart WF, Reed ML, Fanning KM, Serrano $D$, Lipton RB. Sex differences in the prevalence, symptoms, and associated features of migraine, probable migraine and other severe headache: results of the American Migraine Prevalence and Prevention (AMPP) Study. Headache 2013;53:1278-1299. [CrossRef]

4. Maleki N, Linnman C, Brawn J, Burstein R, Becerra L, Borsook D. Her versus his migraine: multiple sex differences in brain function and structure. Brain 2012;135:2546-2559. [CrossRef]

5. Vetvik KG, MacGregor EA. Sex differences in the epidemiology, clinical features, and pathophysiology of migraine. Lancet Neurol 2017;16:76-87. [CrossRef]

6. Wang X-P, Liu J-M, Zhao Y-B. Migraine: Sex-influenced trait model? Med Hypotheses 2008;71:14-21. [CrossRef]

7. Ertas M, Baykan B, Orhan EK, Zarifoglu M, Karli N, Saip S, Onal AE, Siva A. One-year prevalence and the impact of migraine and tension-type headache in Turkey: a nationwide home-based study in adults. J Headache Pain 2012;13:147-157. [CrossRef]

8. Headache Classification Committee of the International Headache Society (IHS). The International Classification of Headache Disorders. Cephalalgia 2018;38:1-211. [CrossRef]

9. Ertaş M, Siva A, Dalkara T, Uzuner N, Dora B, İnan L, İdiman F, Sarica Y, Selçuki D, Şirin H. Oğuzhanoğlu A, Irkeç C, Ozmenoğlu M, Ozbenli T, Oztürk M, Saip S, Neyal M, Zarifoğlu M; Turkish MIDAS group. Validity and reliability of the Turkish Migraine Disability Assessment (MIDAS) questionnaire. Headache 2004:44:786-793. [CrossRef]

10. Bolay H, Ozge A, Saginc P, Orekici G, Uludüz D, Yalın O, Siva A, Bıçakçı \$, Karakurum B, Öztürk M. Gender influences headache characteristics with increasing age in migraine patients. Cephalalgia 2015;35:792-800. [CrossRef]

11. Karlı N, Baykan B, Ertaş M, Zarifoğlu M, Siva A, Saip S, Ozkaya G; Turkish Headache Prevalence Study Group. Impact of sex hormonal changes on tension-type headache and migraine: a cross-sectional population-based survey in 2,600 women. J Headache Pain 2012;13:557-565. [CrossRef]

12. Finocchi C, Strada L. Sex-related differences in migraine. Neurol Sci 2014;35:207-213. [CrossRef]

13. Karlı N, Akış N, Zarifoğlu M, Akgoz S, Irgil E, Ayvacıoğlu U, Çalışır N, Haran $\mathrm{N}$, Akdoğan O. Headache prevalence in adolescents aged 12 to 17: A student-based epidemiological study in Bursa. Headache 2006;46:649-655. [CrossRef]

14. Granella F, Sances G, Pucci E, Nappi R, Ghiotto N, Nappi G. Migraine with aura and reproductive life events: a case control study. Cephalalgia 2000;20:701-707. [CrossRef]

15. Robert C, Bourgeais L, Arreto C-D, Condes-Lara M, Noseda R, Jay T, Villanueva L. Paraventricular hypothalamic regulation of trigeminovascular mechanisms involved in headaches. J Neurosci 2013;33:8827-8840. [CrossRef]
16. Borsook D, Erpelding N, Lebel A, Linnman C, Veggeberg R, Grant $P$, Buettner C, Becerra L, Burstein R. Sex and the migraine brain. Neurobiol Dis 2014;68:200-214. [CrossRef]

17. Russell MB, Ulrich V, Gervil M, Olesen J. Migraine without aura and migraine with aura are distinct disorders. A population-based twin survey. Headache 2002;42:332-336. [CrossRef]

18. Ferrari MD, Klever RR, Terwindt GM, Ayata C, van den Maagdenberg AM Migraine pathophysiology: lessons from mouse models and human genetics. Lancet Neurol 2015;14:65-80. [CrossRef]

19. Li B, Murray RD, Heitlinger LA, Robbins JL, Hayes JR. Is cyclic vomiting syndrome related to migraine? J Pediatr 1999;134:567-572. [CrossRef]

20. Wang Q, Ito M, Adams K, Li BU, Klopstock T, Maslim A, Higashimoto T, Herzog J, Boles RG. Mitochondrial DNA control region sequence variation in migraine headache and cyclic vomiting syndrome. Am J Med Genet 2004;131A:50-58. [CrossRef]

21. Baykan B, Ekizoglu E, Karli N, Kocasoy-Orhan E, Zarifoglu M, Saip S, Siva A Ertas M. Characterization of migraineurs having allodynia: results of a large population-based study. Clin J Pain 2016;32:631-635. [CrossRef]

22. Lipton RB, Bigal ME, Ashina S, Burstein R, Silberstein S, Reed ML, Serrano D, Stewart WF; American Migraine Prevalence Prevention Advisory Group. Cutaneous allodynia in the migraine population. Ann Neurol 2008;63:148158. [CrossRef]

23. Lempert $\mathrm{T}$, Neuhauser $\mathrm{H}$. Epidemiology of vertigo, migraine and vestibular migraine. J Neurol 2009;256:333-338. [CrossRef]

24. Karli N, Zarifoglu M, Calisir N, Akgoz S. Comparison of pre-headache phases and trigger factors of migraine and episodic tension-type headache: do they share similar clinical pathophysiology? Cephalalgia 2005;25:444-451. [CrossRef]

25. Turner L, Molgaard C, Gardner C, Rothrock J, Stang P. Migraine trigger factors in a non-clinical Mexican-American population in San Diego county: implications for etiology. Cephalalgia 1995;15:523-530. [CrossRef]

26. Kelman L. The triggers or precipitants of the acute migraine attack. Cephalalgia 2007;27:394-402. [CrossRef]

27. Johansson A, Bramerson A, Millqvist E, Nordin S, Bende M. Prevalence and risk factors for self-reported odour intolerance: the Skovde populationbased study. Int Arch Occup Environ Health 2005;78:559-564. [CrossRef]

28. Gallai V, Sarchielli P; for the Ad Hoc Committee for the Diagnostic and Therapeutic Guidelines of Migraine and Cluster Headache. Diagnostic and therapeutic guidelines for migraine. Italian Society for the Study of Headaches (SISC). J Headache Pain 2001;2:s125-s129. [CrossRef]

29. Pryse-Phillips WE, Dodick DW, Edmeads JG, Gawel MJ, Nelson RF, Purdy RA, Robinson G, Stirling D, Worthington I. Guidelines for the diagnosis and management of migraine in clinical practice. CMAJ 1997;156:1273-1287.

30. Dzaja A, Arber S, Hislop J, Kerkhofs M, Kopp C, Pollmächer T, Polo-Kantola P, Skene DJ, Stenuit P, Tobler I, Porkka-Heiskanen T. Women's sleep in health and disease. J Psychiatr Res 2005;39:55-76. [CrossRef] 